\title{
Characterization of $\mathrm{RF}$-sputtered garnet films
}

\author{
RAMBILAS and D BAHADUR \\ Idvanced Centre for Matcrials Science, Indian Institute of Technology, Kanpur 208016. \\ India \\ MS received 2 November 1987
}

Ibstract. Noncrystalline garnet films of nominal composition $\mathrm{Y}_{3} \mathrm{Fe}_{5} \mathrm{O}_{12}$ and $\mathrm{Y}_{2} \mathrm{GdFe}_{5} \mathrm{O}_{12}$ were synthesized by $\mathrm{RF}$ sputtering. The $\mathrm{AC}$ and $\mathrm{DC}$ resistivity data have been discussed in line with the model of Mott and Davis where conduction becurs through excitation of carrices into localized states at the band edges and hopping at energies close to the band tails.

Keywords. RF" sputtering; garnet films.

\section{Introduction}

Noncrystalline garnets have been synthesized by several methods and characterized before and after crystallization (Popma and Van Diepen 1974; Roy et al 1985; Bahadur and Rai 1980). Thin films made by spray pyrolysis (Bahadur et al 1986), flash evaporation (Bahadur et al 1984) or reactive sputtering (Sawatzky and Kay 1968) yielded an amorphous structure, which upon suitable heat treatment, gave crystalline garnets. Such films showed very interesting structural, electronic and magnetic properties. Garnet films of nominal composition $\mathrm{Y}_{3} \mathrm{Fe}_{5} \mathrm{O}_{12}$ (YIG) and $\mathrm{Y}_{2} \mathrm{GdFe}_{5} \mathrm{O}_{12}(\mathrm{Gd}-\mathrm{YIG})$ by $r$.f. sputtering and their structural and electronic properties were studied, the results of which are presented here.

\section{Experimental}

Thin films were made by r.f. sputtering of the hot-pressed target of appropriate composition by Nordiko NM-400 sputtering module on quartz substrates. Gold electrodes were deposited on the film for thickness as well as for electrical measurements. The standard error in thickness measurement is $\pm 20 \AA$. The thickness of YIG and Gd-YIG films on which all measurements were carried out were $1400 \AA$ and $1300 \AA$ respectively.

The X-ray diffractions were recorded for the as-prepared and heat-treated samples with a Rich-Seifert isodebyeflex 2002 diffractometer with $\mathrm{Cu}-\mathrm{K}_{\alpha}$ target between 20 values of $25^{\prime \prime}$ and $50^{\circ}$. Electron micrographs and diffractions were recorded with a transmission electron microscope (Philips 301). The AC and DC resistivity were measured with a Keithley electrometer and HP impedance bridge (model HP $4192 \mathrm{~A}$ ). I-V characteristics were recorded at intermittent temperatures to see its linearity.

\section{Results and discussion}

The as-prepared films are amorphous as determined by X-ray diffraction. Partial crystallization occurs only for samples heat-treated above $800^{\circ} \mathrm{C}$ for both the YIG 
and Gd-YIG compositions. It may be noted that the spray-pyrolysed films of the same composition crystallise at $650^{\circ} \mathrm{C}$ (Bahadur et al 1986). Therefore it appears that the r.f. sputtered films are more stable. Secondly, for the spray-pyrolysed films we observe the exsolution of $\mathrm{Fe}_{2} \mathrm{O}_{3}$ phase along with garnet phase for all the heat treatments we had tried (Bahadur et al 1986). In the case of r.f. sputtered films it had been possible to index all the lines to garnet phase for a particular heat treatment. Table 1 lists the $d$ - and possible $h k l$ values for the sample Gd-YIG heat-treated in two different conditions. When heat-treated at $1100^{\circ} \mathrm{C}$ for $1 \mathrm{hr}$, it gives strong lines of both the garnet and orthoferrite phase. The same sample when heat-treated at $1000^{\circ} \mathrm{C}$ for $2 \mathrm{hr}$ gives a single garnet phase. In this case $1000^{\circ} \mathrm{C}$ appears as the right growth temperature for the garnet phase. Figure 1 shows a typical electron micrograph for the sample Gd-YIG heat-treated at $700^{\circ} \mathrm{C}$. The inset shows its selected area

Table 1. X-ray diffraction data for Gd-YIG film heattreated in two different conditions (data taken only between $2 \theta=25^{\circ}$ and $2 \theta=50^{\circ} \mathrm{C}$ ).

\begin{tabular}{|c|c|c|c|}
\hline \multicolumn{2}{|c|}{$\begin{array}{l}\text { Heat treated } \\
\text { at } 1000^{\circ} \mathrm{C} \text { for } 2 \mathrm{hr}\end{array}$} & \multicolumn{2}{|c|}{$\begin{array}{l}\text { Heat treated at } \\
1100 \mathrm{C} \text { for } 1 \mathrm{hr}\end{array}$} \\
\hline$d$ value & $h k l$ & $d$ value & $h k l$ \\
\hline $2.96(\mathrm{~S})$ & 400 & $3 \cdot 32$ (S) & 321 \\
\hline $2 \cdot 76(\mathrm{~S})$ & 420 & $3.02(\mathrm{~S})$ & 400 \\
\hline $2 \cdot 51(\mathrm{M})$ & 422 & $2.90(W)$ & $-\cdots-$ \\
\hline $2 \cdot 19$ (W) & 440 & $2 \cdot 80(\mathrm{~W})$ & $420^{*}$ \\
\hline $2.09(\mathrm{~W})$ & 532 & $2 \cdot 70(\mathrm{~S})$ & $*$ \\
\hline $1.83(\mathrm{~S})$ & 444 & - & - \\
\hline
\end{tabular}

Note: $h k l$ values are w.r.t. YIG phase: The intensity is given in brackets: $\mathrm{S}$, strong; $\mathrm{M}$, medium; W, weak.

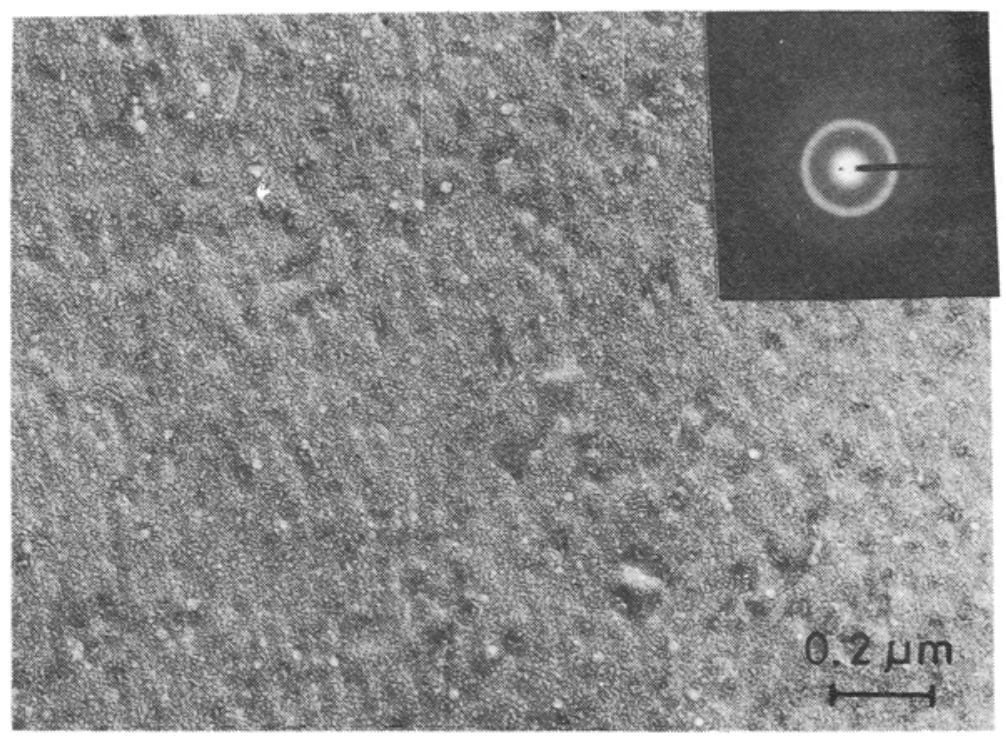

Figure 1. Eiectron micrograph of nominal composition $\mathrm{Y}_{2} \mathrm{GdFe}_{5} \mathrm{O}_{12}$ heat-treated at $700 \mathrm{C}$ for $1 \mathrm{hr}$. Inset shous the corresponding electron diffraction. 
electron diffraction from which an amorphous structure is evident. The micrograph exhibits a fairly homogeneous structure. Figure 2 shows the plot of $\log \rho_{\mathrm{DC}}$ vs $1000 / T$ for YIG and Gd-YIG and figure 3 the representative plot of $\log \rho_{\mathrm{AC}}$ vs $\log f$ for the sample Gd-YIG at two different temperatures. The activation energies evaluated from figure 2 and $S$ values from figure 3 along with temperature ranges are given in table 2 .

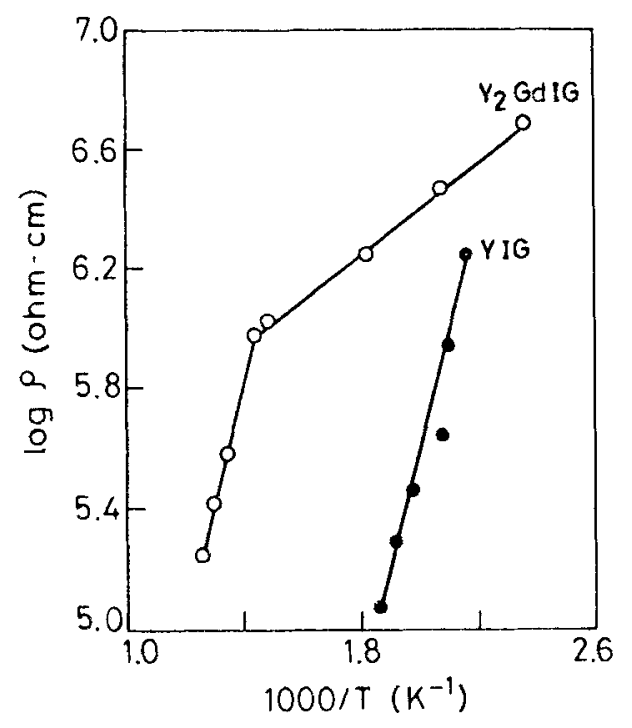

Figure 2. Plor of $\log \rho_{\text {d.c. }}$ ws $1000 \mathrm{~T}$ for films of nominal composition $\mathrm{Y}_{3} \mathrm{Fe}_{5} \mathrm{O}_{12}$ and $\mathrm{Y}_{2} \mathrm{GdFe}_{5} \mathrm{O}_{12}$.

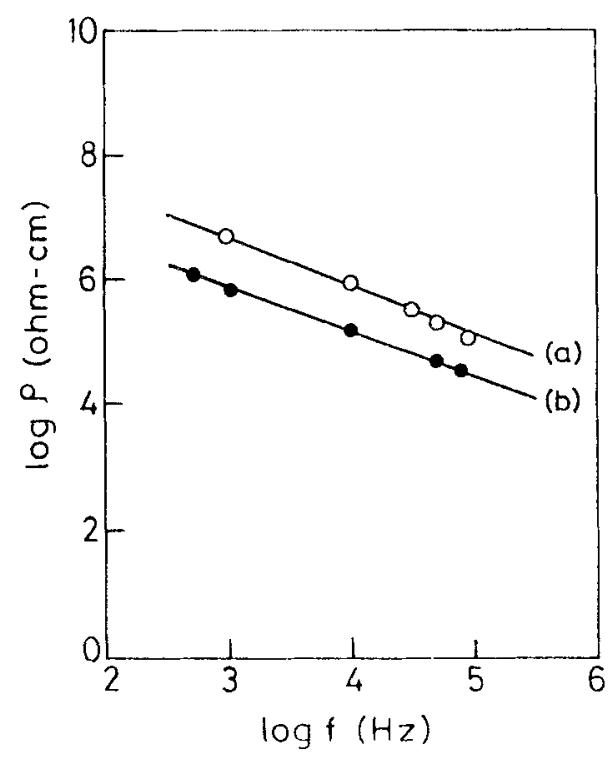

Figure 3. Plot of $\log p_{\mathrm{atc}} v \mathrm{v} \log f$ for film of nominal composition $\mathrm{Y}_{2} \mathrm{GdFe}_{5} \mathrm{O}_{12}$ at temperatures a. $380^{\circ} \mathrm{K}$ and $\quad$ b. $650^{\prime \prime} \mathrm{K}$. 
Table 2. Activation energies and $S$ values in different ranges for films of YIG and $\mathrm{Y}_{2} \mathrm{GdIG}$.

\begin{tabular}{lcccl}
\hline Sample & $\begin{array}{c}\text { Thickness } \\
(\AA)\end{array}$ & $\begin{array}{c}\text { Range } \\
(\mathrm{K})\end{array}$ & $\begin{array}{c}\text { Activation } \\
\text { energies }(\mathrm{eV})\end{array}$ & \multicolumn{1}{l}{$S$-values } \\
\hline Y1G & 1400 & $420-600$ & 0.34 & $\begin{array}{l}0.62(670 \mathrm{~K}) \\
0.93(\mathrm{RT})\end{array}$ \\
Y ${ }_{2}$ GdIG & 1300 & $420-690$ & 0.07 & $0.8(380 \mathrm{~K})$ \\
& & $690-770$ & 0.34 & $0.75(650 \mathrm{~K})$ \\
\hline
\end{tabular}

Note: The parentheses of the last column gives the temperature of mcasurement.

The sample (id-YIG exhibits two activation energies whereas the YIG sample gives a single activation energy for the temperature range studied. The value of $E_{a}$ for YIG is the same as that observed for Gd-YIG in the high temperature region. A similar observation has been made in bulk YIG and Gd-YIG (Bahadur et al 1981). It appears, therefore, that the localized sites through which hopping occurs are essentially the same. However, for lower temperature region where Gd-YIG exhibits an activation energy of $0.07 \mathrm{eV}$, Gd-substitution may be responsible for the generation of some new localized states which is closer to the fermi level. Another noteworthy feature of the DC resistivity data is the lower values of resistivity and activation energies compared to the bulk sample. Lowering of activation energies was similarly observed in flash-evaporated garnet films (Bahadur et al 1984). This is attributed to the tails of localized states and the band of compensated levels in amorphous systems which could lower the activation energies. It is interesting that the frequency dependence of resistivity varies approximately as $\sigma^{S}$ where $S$ lies between 0.6 and 1 .

In the light of these results, it is possible to assign the electronic conduction due to the excitation of carriers into localized states at the band edges and hopping at energies close to band tails (Mott and Davis 1980; Nagels 1979). In this model a narrow tail of localized states at the extremities of the valence and conduction band and a band of localized levels near the middle of the gap exist. According to this, three conduction mechanisms are possible: (i) The extended state conduction, which demands a frequency-independent conductivity is ruled out, (ii) the conduction in localized states at the fermi energy may not be operative as indicated by the exponential dependence of $\rho(f)$ with temperature and (iii) this is then a characteristic of conduction in band tails which appears to be the mode of conduction in the system.

\section{Acknowledgement}

Financial support by the Department of Atomic Energy, Government of India is acknowledged.

\section{References}

Bahadur D and Rai K N 1980 Maler. Res. Bull. 15510

Bahadur D, Roy D and Ram S 1986 Adn. Ceram. 16651

Bahadur D, Roy D. Singh B and Saran D 1984 Bull. Mater. Sci. 653

Bahadur D. Prakash O and Kumar D 1981 Bull. Mater. Sci. 3325 
Mott N F and Davis E A 1980 Electronic processes in foncrystalline materials (Oxford: Clarendon Press) p. 199

Nagels D 1979 in: Amorphous semiconductors (ed) M H Brodsky (Berlin: Heidelberg and New York: Springer Verlag)

Popma J A and Vandiepen A M 1974 Mater, Res. Bull. 91119

Roy D, Bhatnagar R and Bahadur D 1985 J. Mater. Sci. 20157

Sawatzky K and Kay E 1968 J. Appl. Phys. 394700 